\title{
Backbone and side-chain assignments of a tethered complex between LMO4 and DEAF-1
}

\author{
Soumya Joseph • Ann H. Y. Kwan • \\ Joel P. Mackay • Liza Cubeddu • \\ Jacqueline M. Matthews
}

Received: 3 January 2013/Accepted: 8 February 2013/Published online: 16 February 2013

(C) Springer Science+Business Media Dordrecht 2013

\begin{abstract}
The transcriptional regulator LMO4 and the transcription factor DEAF-1 are both essential for brain and skeletal development. They are also implicated in human breast cancers; overexpression of LMO4 is an indicator of poor prognosis, and overexpression of DEAF-1 promotes epithelial breast cell proliferation. We have generated a stable LMO4-DEAF-1 complex comprising the C-terminal LIM domain of LMO4 and an intrinsically disordered LMO4-interaction domain from DEAF-1 tethered by a glycine/serine linker. Here we report the ${ }^{1} \mathrm{H},{ }^{15} \mathrm{~N}$ and ${ }^{13} \mathrm{C}$ assignments of this construct. Analysis of the assignments indicates the presence of structure in the DEAF-1 part of the complex supporting the presence of a physical interaction between the two proteins.
\end{abstract}

Keywords LMO4 - DEAF-1 - Transcriptional complex · Embryonic development $\cdot$ Breast cancer

\section{Biological context}

The LIM-domain only protein, LMO4, and the transcription factor DEAF-1 (Deformed epidermal autoregulatory

Electronic supplementary material The online version of this article (doi:10.1007/s12104-013-9470-x) contains supplementary material, which is available to authorized users.

S. Joseph · A. H. Y. Kwan · J. P. Mackay · J. M. Matthews ( $\square)$ School of Molecular Bioscience, University of Sydney, Sydney, NSW 2006, Australia

e-mail: jacqui.matthews@sydney.edu.au

L. Cubeddu

School of Science and Health, University of Western Sydney, Sydney, NSW 2751, Australia
factor-1/NUDR/Suppressin) are co-expressed in a range of cell types (Huggenvik et al. 1998; Kenny et al. 1998), exhibit similar knock-in or knock-out phenotypes (Barker et al. 2008), and physically interact (Cubeddu et al. 2012; Sugihara et al. 1998). Therefore, it is likely that LMO4 and DEAF-1 perform at least some of their cellular functions as a complex. Both LMO4 and DEAF-1 are implicated in mouse embryonic development. In particular, both proteins have important roles in neural tube closure and skeletal patterning (Hahm et al. 2004). LMO4 is overexpressed in human breast cancers, where it is indicative of poor prognosis (Sum et al. 2005). Overexpression of DEAF-1 enhances the proliferation of human breast epithelial cells in vitro and mouse epithelial cells in vivo (Barker et al. 2008). LMO4 consists of two LIM (LIN-11/ISL1/MEC-3) domains, which are non-classical zinc fingers that mediate protein-protein interactions, and is thought to nucleate transcriptional complexes. In contrast, DEAF-1 contains multiple domains including a DNA-binding SAND (Sp100/ AIRE1/NucP41/75/DEAF-1) domain, a nuclear localisation signal, a protein-interacting MYND (Myeloid translocation protein 8/Nervy/DEAF-1) domain and a coiled-coil domain that contains a nuclear export signal (Jensik et al. 2004).

Recombinant LMO4, expressed in isolation, is mostly insoluble and tends to aggregate. These problems can be overcome by engineering 'tethered complexes' with LMO4 binding partners, which form native-like interactions. We produced a stable tethered complex between the C-terminal LIM domain of LMO4 (LMO4 $\left.4_{77-147}\right)$ and DEAF- $1_{404-418}$, which is part of a region in DEAF-1 that was shown to mediate interactions with LMO4 (Cubeddu et al. 2012). We have assigned the backbone and side-chain resonances of $\mathrm{LMO}_{77-147}-\mathrm{DEAF}-1_{404-418}$. The structure of the

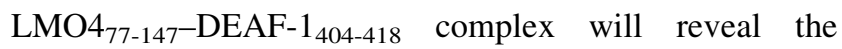
molecular details of this interaction and provide insight 
into the formation of higher order transcriptional complexes.

\section{Methods and experiments}

Protein production

$\mathrm{LMO}_{77-147}-\mathrm{DEAF}-1_{404-418}$ was generated using overlap extension PCR and cloned into pGEX-2T to produce a tethered construct tagged with glutathione $S$-transferase (GST). The construct comprises residues 77-147 of mouse LMO4 (NCBI accession: NP_001155242), an 8-residue linker (GGSGGSGS) followed by residues 404-418 of canonical DEAF-1 from mouse (NM_016874). Isotopically labelled protein was produced as described previously (Marley et al. 2001). In brief, transformed Rosetta 2 Escherichia coli cells were cultured at $37{ }^{\circ} \mathrm{C}$ in LB media containing carbenicillin $\left(100 \mu \mathrm{g} \mathrm{mL}^{-1}\right)$, chloramphenicol (34 $\mu \mathrm{g} \mathrm{mL}^{-1}$ ) and $0.5 \%$ glucose to an $\mathrm{OD}_{600 \mathrm{~nm}}$ of $\sim 0.7$. The cells were transferred to minimal media containing isotopes of interest, carbenicillin and chloramphenicol. They were allowed to recover for $1 \mathrm{~h}$ at $20^{\circ} \mathrm{C}$ and protein expression was induced with $0.4 \mathrm{mM}$ isopropyl $\beta$-D-thiogalactopyranoside for $16 \mathrm{~h}$ at $20^{\circ} \mathrm{C}$.

\section{Purification}

The cells were resuspended in $20 \mathrm{mM}$ Tris-base; $\mathrm{pH} 8.0$, $150 \mathrm{mM} \mathrm{NaCl}$ and $1 \mathrm{mM}$ DTT (buffer A) containing $10 \%$ glycerol and EDTA-free protease inhibitor cocktail (1 tablet/50 mL), lysed with the addition of lysozyme $\left(100 \mu \mathrm{g} \mathrm{mL}^{-1}\right)$, freeze-thawing $(3 \times)$, addition of DNaseI $\left(10 \mu \mathrm{g} \mathrm{mL}^{-1}\right)$ and sonication. The cleared lysate was applied to glutathione resin equilibrated in buffer $\mathrm{A}$ and incubated for $1 \mathrm{~h}$ at $4{ }^{\circ} \mathrm{C}$. The resin was washed with 20 column volumes (CVs) of buffer A, $40 \mathrm{CVs}$ of buffer A containing $300 \mathrm{mM} \mathrm{NaCl}$ and then $2 \mathrm{CVs}$ of $20 \mathrm{mM}$ HEPES sodium salt; pH 7.0, $150 \mathrm{mM} \mathrm{NaCl}, 1 \mathrm{mM}$ DTT and $2 \mathrm{mM} \mathrm{CaCl}_{2}$ (buffer B). GST-LMO4 ${ }_{77-147}$-DEAF$1_{404-418}$ was eluted from the resin in buffer B containing $50 \mathrm{mM}$ reduced glutathione and cleaved by treatment with thrombin $\left(20 \mathrm{U}, 16 \mathrm{~h}, 25^{\circ} \mathrm{C}\right) . \mathrm{LMO}_{77-147}-\mathrm{DEAF}-1_{404-418}$ was separated from GST by size exclusion chromatography (preparative grade Superdex 75; GE Healthcare) in $20 \mathrm{mM}$ sodium acetate; $\mathrm{pH} 5.0,50-150 \mathrm{mM} \mathrm{NaCl}$ and $1 \mathrm{mM}$ Tris (2-chloroethyl) phosphate hydrochloride (TCEP.HCl). Fractions containing $\mathrm{LMO}_{77-147}-\mathrm{DEAF}-1_{404-418}$ were pooled and concentrated, with the addition of chloramphenicol and EDTA-free protease inhibitor (Roche) to $\sim 0.5 \mathrm{mM}$, using a stirred-cell concentrator and then freeze-dried. The freeze-dried protein was stored at $-20{ }^{\circ} \mathrm{C}$ until required.
NMR experiments

Freeze-dried LMO4 $4_{77-147}-\mathrm{DEAF}-1_{404-418}$ was resuspended in either $\mathrm{H}_{2} \mathrm{O}(90 \%)$ and $\mathrm{D}_{2} \mathrm{O}(10 \%)$, or $\mathrm{D}_{2} \mathrm{O}$ alone, such that the sample contained $20 \mathrm{mM}$ sodium acetate $\mathrm{pH} 5.0$, $35 \mathrm{mM} \mathrm{NaCl}, 0.5 \mathrm{mM}$ TCEP. $\mathrm{HCl}, 34 \mu \mathrm{g} \mathrm{mL}{ }^{-1}$ chloramphenicol and EDTA-free protease inhibitor cocktail (1 tablet/50 mL). NMR experiments were conducted at a protein concentration $(c)$ of $\sim 0.5 \mathrm{mM}$ as estimated by the equation $\mathrm{A}_{215 \mathrm{~nm}}-\mathrm{A}_{225 \mathrm{~nm}} \times 144=c\left(\mu \mathrm{g} \mathrm{mL}^{-1}\right)$, where $\mathrm{A}_{215 \mathrm{~nm}}$ and $\mathrm{A}_{225 \mathrm{~nm}}$ are the absorbance at 215 and $225 \mathrm{~nm}$, respectively. Proton chemical shifts were referenced to 4,4dimethyl-4-silapentanesulfonic acid (DSS) at $0.00 \mathrm{ppm}$.

${ }^{13} \mathrm{C}$ and ${ }^{15} \mathrm{~N}$ chemical shifts were referenced indirectly to the same signal. NMR experiments were recorded at $298 \mathrm{~K}$ on either a 600 or $800 \mathrm{MHz}$ spectrometer (Bruker Avance III) equipped with a 5-mm TCI CryoProbe (Bruker). The spectra recorded included ${ }^{15} \mathrm{~N}-\mathrm{HSQC},{ }^{13} \mathrm{C}-\mathrm{HSQC}, \mathrm{CBCA}(\mathrm{CO}) \mathrm{NH}$, $\mathrm{HNCACB}, \mathrm{HCC}(\mathrm{CO}) \mathrm{NH}, \mathrm{HNCO}, \mathrm{HN}(\mathrm{CA}) \mathrm{CO}$, (H)CCHTOCSY, HBCBCGCDCEHE, HBCBCGCDHD (Yamazaki et al. 1993), histidine-HSQC (Pelton et al. 1993), ${ }^{15} \mathrm{~N}-\mathrm{NO}-$ ESY, ${ }^{13} \mathrm{C}$-aliphatic-NOESY, ${ }^{1} \mathrm{H}-\mathrm{COSY},{ }^{1} \mathrm{H}-\mathrm{TOCSY}$ and ${ }^{1}$ H-NOESY.

\section{Data processing}

Data were processed using Topspin (Bruker Biospin) and assignments were made using Sparky (T. D. Goddard and D. G. Kneller, University of California at San Francisco). TALOS+ (Shen et al. 2009) was used to predict secondary structure based on $\mathrm{C}_{\alpha}, \mathrm{C}_{\beta}, \mathrm{H}_{\mathrm{N}}, \mathrm{N}$ and $\mathrm{C}^{\prime}$ shifts.

\section{Assignments and data deposition}

The tethered intra-molecular complex between $\mathrm{LMO}_{77}$ ${ }_{147}-$ DEAF- $1_{404-418}$ has 88 residues derived from the native proteins (Fig. 1a). The first two residues (glycine-1 and serine-2) remain from thrombin cleavage of the GST affinity tag. The artificial eight-residue glycine/serine linker (901-908) tethers the C-terminus of LMO4 ${ }_{77-147}$ to the $\mathrm{N}$-terminus of DEAF- $1_{404-418}$. The assigned amide groups are shown on the ${ }^{15} \mathrm{~N}-\mathrm{HSQC}$ (Fig. 2); residues corresponding to LMO4 and DEAF-1 are numbered as they appear in the native, full-length proteins. All assigned $\mathrm{C}_{\alpha}$ and $\mathrm{C}_{\beta}$ shifts were within twice the standard deviation of the average chemical shift reported in the BMRB. Assignments could not be made for glycine-1. Backbone assignments for DEAF- $1_{404-418}$ are complete apart from $\mathrm{A} 405-\mathrm{C}^{\prime}$ and $92 \%$ of the side-chain atoms have been assigned. Assignments for the backbone of $\mathrm{LMO}_{77-147}$ are near complete $(98 \%)$ and $85 \%$ of the side-chain atoms have been assigned. Carbon atoms on aromatic rings were 
Fig. 1 Comparison of secondary structure prediction and chemical shifts of

$\mathrm{LMO}_{77-147}-$ DEAF-1 $_{404-418}$. a Secondary structure prediction the primary sequence of $\mathrm{LMO}_{77-147}-\mathrm{DEAF}-1_{404-418}$; sheet (arrow), helix (spiral) and coil (line) are represented. For comparison, the secondary structure of LMO4 from the high-resolution crystal structure (1RUT) is shown in black. b Difference between secondary $\mathrm{C}_{\alpha}$ and $\mathrm{C}_{\beta}$ shifts $\left(\delta \mathrm{C}_{\alpha}-\delta \mathrm{C}_{\beta} ; \delta\right.$ represents deviations of chemical shifts from random coil values of $C_{\alpha}$ or $C_{\beta}$ ) for each residue. Consecutive residues that have large positive or negative differences $( \pm 3 \mathrm{ppm})$ from random coil values indicate presence of $\alpha$-helix or $\beta$-sheet, respectively from TALOS + is shown below

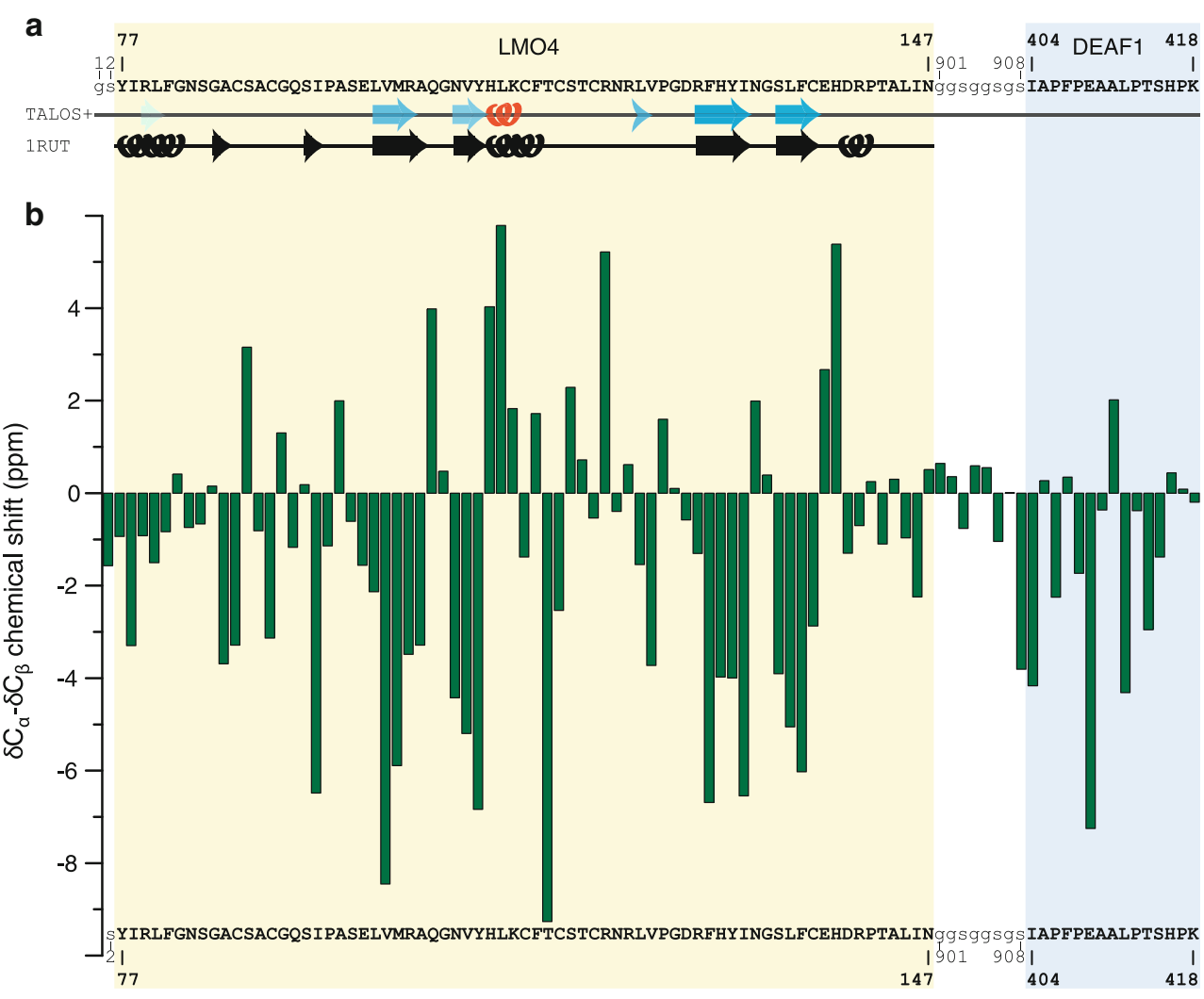

Fig. $2{ }^{15} \mathrm{~N}$-HSQC spectrum of LMO4 $_{77-147}$-DEAF-1 ${ }_{404-418}$ ( $\sim 0.5 \mathrm{mM}$ ) showing backbone and side-chain amide resonances. Asterisks indicate peaks that have been aliased. The spectrum was collected at a proton resonance frequency of $600 \mathrm{MHz}$ at $298 \mathrm{~K}$ in $20 \mathrm{mM}$ sodium acetate $\mathrm{pH} 5.0,35 \mathrm{mM}$ $\mathrm{NaCl}, 0.5 \mathrm{mM}$ TCEP.HCl, $34 \mu \mathrm{g} \mathrm{mL}^{-1}$ chloramphenicol and EDTA-free protease inhibitor cocktail (Roche)

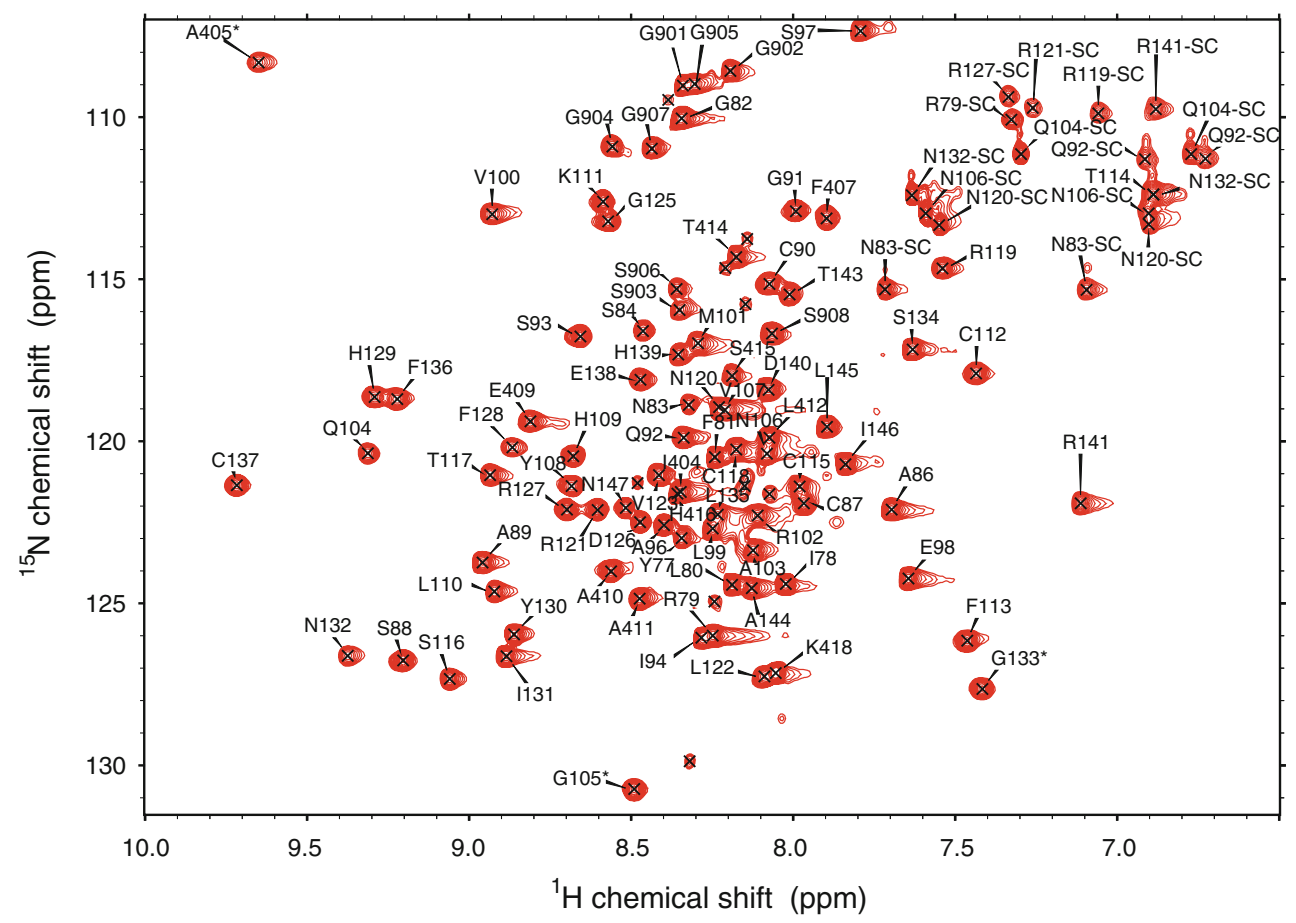

not assigned, although resonances are assigned for most carbon bound protons within these rings. All histidine residues were singly protonated on $\mathrm{N}_{\varepsilon 2}$. Backbone and side-chain assignments for $\mathrm{LMO}_{77-147}$-DEAF- $1_{404-418}$ have been deposited in the BMRB (deposition number
18898). Note that in early preparations, a second, weaker set of signals was observed in the ${ }^{15} \mathrm{~N}-\mathrm{HSQC}$ spectrum. These signals were clustered between 7.8 and $8.5 \mathrm{ppm}$ in the ${ }^{1} \mathrm{H}$ dimension (Figure S1). Freeze-drying of the purified protein eliminated these additional signals. 
Secondary structure predictions based on chemical shift data were carried out using TALOS+ (Fig. 1a). The predicted secondary structure of $\mathrm{LMO}_{77-147}$ is similar to the high resolution crystal structure of LMO4 in complex with Ldb1 (1RUT). Even though a helical structure is predicted for three consecutive residues, H109-K111, at least four consecutive residues are required to make a complete helical turn. With the exception of S908, the chemical shift differences $\left(\delta \mathrm{C}_{\alpha}-\delta \mathrm{C}_{\beta}\right)$ calculated for residues in the glycine/serine linker (901-908) are close to values expected in random coils (Fig. 1b), indicating that this sequence is most likely disordered, as intended. ${ }^{15} \mathrm{~N}-\mathrm{HSQC}$ spectra were also collected for constructs containing either a longer (11-residue) synthetic glycine/serine linker, or a 5-residue N-terminal extension of DEAF-1 (LMO4 ${ }_{77-147}$-DEAF$\left.1_{399-418}\right)$. These spectra are very similar to the original $\mathrm{LMO}_{77-147}$-DEAF- $1_{404-418}$ construct (Figure S2 and S3) suggesting that the structures of the constructs are also similar. In particular, resonances that correspond to DEAF$1_{404-418}$ are maintained, suggesting that the original construct allows native-like complex formation between LMO4 and DEAF-1.

In contrast to most of the residues in the glycine/serine linker, although DEAF- $1_{404-418}$ is predicted to be disordered by PONDR ${ }^{\circledR}$, some of backbone chemical shifts observed for the DEAF-1 peptide in the intra-molecular complex differ significantly from those expected of residues in random coils, suggesting that this region is structured in the context of $\mathrm{LMO}_{77-147}-\mathrm{DEAF}-1_{404-418}$ (Fig. 1b). To further support the argument for complex formation, a preliminary analysis of the NOE data from ${ }^{15} \mathrm{~N}-\mathrm{NOESY}$ and ${ }^{13} \mathrm{C}$-NOESY spectra was carried out. NOEs could be unambiguously assigned as being between DEAF- $1_{404-411}$ and LMO4 $4_{77-147}$ protons, which suggests that an interaction occurs between those regions in this construct.

Acknowledgments S.J. was supported by an Australian Postgraduate Award. J.P.M. and J.M.M. were supported by senior research fellowships from the National Health and Medical Research Council of Australia (NHMRC). L.C. was supported by the Australian National Breast Cancer Foundation Postdoctoral Fellowship. This project was supported by grants from the Australian Research Council and NHMRC. S.J. thanks L. Wilkinson-White, V. K. Morris, Q. Ren, S. Setiyaputra and M. R. O'Connell for their help with using NMR spectra and chemical shift analysis programs.
Conflict of interest The authors declare they have no conflicts of interest.

\section{References}

Barker HE, Smyth GK, Wettenhall J, Ward TA, Bath ML, Lindeman GJ, Visvader JE (2008) Deaf-1 regulates epithelial cell proliferation and side-branching in the mammary gland. BMC Dev Biol 8:94

Cubeddu L, Joseph S, Richard DJ, Matthews JM (2012) Contribution of DEAF-1 structural domains to the interaction with the breast cancer oncogene LMO4. PLoS One 7(6):e39218

Hahm K, Sum EYM, Fujiwara Y, Lindeman GJ, Visvader JE, Orkin SH (2004) Defective neural tube closure and anteroposterior patterning in mice lacking the LIM protein LMO4 or its interacting partner Deaf-1. Mol Cell Biol 24(5):2074-2082

Huggenvik JI, Michelson RJ, Collard MW, Ziemba AJ, Gurley P, Mowen KA (1998) Characterization of a nuclear deformed epidermal autoregulatory factor-1 (DEAF-1)-related (NUDR) transcriptional regulator protein. Mol Endocrinol 12(10): 1619-1639

Jensik PJ, Huggenvik JI, Collard MW (2004) Identification of a nuclear export signal and protein interaction domains in deformed epidermal autoregulatory factor-1 (DEAF-1). J Biol Chem 279(31):32692-32699

Kenny DA, Jurata LW, Saga Y, Gill GN (1998) Identification and characterization of LMO4, an LMO gene with a novel pattern of expression during embryogenesis. Proc Natl Acad Sci USA 95(19):11257-11262

Marley J, Lu M, Bracken C (2001) A method for efficient isotopic labeling of recombinant proteins. J Biomol NMR 20(1):71-75

Pelton JG, Torchia DA, Meadow ND, Roseman S (1993) Tautomeric states of the active-site histidines of phosphorylated and unphosphorylated IIIGlc, a signal-transducing protein from Escherichia coli, using two-dimensional heteronuclear NMR techniques. Protein Sci 2(4):543-558

Shen Y, Delaglio F, Cornilescu G, Bax A (2009) TALOS+: a hybrid method for predicting protein backbone torsion angles from NMR chemical shifts. J Biomol NMR 44(4):213-223

Sugihara TM, Bach I, Kioussi C, Rosenfeld MG, Andersen B (1998) Mouse deformed epidermal autoregulatory factor 1 recruits a LIM domain factor, LMO-4, and CLIM coregulators. Proc Natl Acad Sci USA 95(26):15418-15423

Sum EYM, Segara D, Duscio B, Bath ML, Field AS, Sutherland RL, Lindeman GJ, Visvader JE (2005) Overexpression of LMO4 induces mammary hyperplasia, promotes cell invasion, and is a predictor of poor outcome in breast cancer. Proc Natl Acad Sci USA 102(21):7659-7664

Yamazaki T, Forman-Kay JD, Kay LE (1993) Two-dimensional NMR experiments for correlating ${ }^{13} \mathrm{Cb}$ and ${ }^{1} \mathrm{Hd} / \mathrm{e}$ chemical shifts of aromatic residues in ${ }^{13} \mathrm{C}$-labeled proteins via scalar couplings. J Am Chem Soc 115(23):11054-11055 